\title{
Chemical constituents, antimicrobial and antioxidant activity of essential oil of Citrus limetta var. Mitha (sweet lime) peel in Pakistan
}

\author{
Shabnam Javed ${ }^{1 \star}$, Rauf Ahmad $^{2}$, Khurram Shahzad $^{3}$, Shaista Nawaz $^{3}$, Salman Saeed ${ }^{3}$ and \\ Yasar Saleem ${ }^{3}$ \\ ${ }^{1}$ Center for Undergraduate Studies, University of Punjab, Lahore-54590 Pakistan. \\ ${ }^{2}$ Centre for Environmental Protection Studies, PCSIR Laboratories Complex, Lahore-54600, Pakistan. \\ ${ }^{3}$ Food and Biotechnology Research Center, Pakistan Council of Scientific and Industrial Research Laboratories \\ Complex, Lahore-54600, Pakistan.
}

Accepted 5 June, 2013

\begin{abstract}
The essential peel oil of Citrus limetta var. Mitha (Sweet lime) extracted by hydro-distillation was assessed for chemical constituents, antimicrobial and antioxidant activity. Gas chromatographic analysis identified 17 constituents among which limonene (95.98\%) was found as major component followed by camphene $(1.79 \%)$, while the remaining terpenes were less than $1 \%$. The results of antimicrobial activity of essential oil tested by disc diffusion method, against different against bacteria and fungi showed that it exhibited maximum zone of inhibition against Bacillus cereus ATCC 14579 (28 $\mathrm{mm}$ ) and Bacillus subtilis ATCC $6633(26 \mathrm{~mm})$ followed by Staphylococcus aureus ATCC 25923 (21 $\mathrm{mm}$ ), where as the minimum zone of inhibition was shown by Fusarium oxysporum ATCC 48122 (11 $\mathrm{mm})$ after $48 \mathrm{~h}$ of incubation at their respective temperature $\left(37^{\circ} \mathrm{C}\right.$ for bacteria and $25^{\circ} \mathrm{C}$ for fungi). The inhibition zones, measured after 48 and $96 \mathrm{~h}$, showed that it was active against all tested bacteria and fungi. The results of its antioxidant activity showed that it was able to reduce the stable radical 1diphenyl-2-picrylhydrazyl (DPPH) to yellow-colored DPPH-H reaching $87.77 \%$ of DPPH scavenging effect at its $100 \%$ concentration comparative to ascorbic acid as reference standard being a strong antioxidant reagent. The results of our study showed that essential oil of $C$. limetta var. Mitha peel can be an effective medicine against different pathogenic microbes.
\end{abstract}

Key words: Citrus limetta var. Mitha, essential oil, antimicrobial activity, antioxidant, pathogenic microbes.

\section{INTRODUCTION}

Medicinal plants have been used for centuries as remedies for human diseases because they contain chemical components of therapeutic value (Nostro et al., 2000). According to the World Health Organization (WHO) in 2008 , more than $80 \%$ of the world's population relies on traditional medicine for their primary healthcare needs (Pierangeli, et al., 2009). The genus citrus (Rutaceae) comprises of trees, shrubs and herbs of various sizes and uses. They are the most widespread arboreal plants in the world and represent one of the most important crops (Jacquemond et al., 2002). Citrus fruits belong to six genera (Fortunella, Eremocitrus, Clymendia, Poncirus, Microcitrus and Citrus), which are native to the tropical and subtropical regions of Asia, but the major commercial fruits belong to genus Citrus. The genus citrus is represented by 10 species in Pakistan (Nasir and Ali, 1978). Citrus limetta var. Mitha (sweet lime) is one of them. It is a popular indigenous citrus fruit 
relished for its cooling and therapeutic effects and also as a culinary delight in some parts of the subcontinent. In the traditional indigenous medicinal system, sweet lime juice is valued for curing fever, malaria and jaundice (Murphy, 1999).

One of the important products of citrus fruits is the essential oil, which is obtained from citrus peels (Mondello et al., 2005). Scientists from divergent fields are investigating the essential oils of different plants with an eye to their medicinal usefulness. These oils are considered to be one of the potential sources for the screening of anticancer, antimicrobial, antioxidant, and free radical scavenging agents (Shabbir et al., 2009). Phenolic compounds present in essential oils have been recognized as the bioactive components for the antimicrobial activity. Most plant phenolic compounds are classified as generally recognized as safe (GRAS) substances; therefore they could be used to prevent growth of many food-borne and food spoilage microorganisms in foods. Such natural compounds are believed to demonstrate anticarcinogenic potential and offer diverse health-promoting effects because of their antioxidant attributes (Liu et al., 2008). The essential oils possessed appreciable antioxidant and radical scavenging activities revealing potential for therapeutic applications (Hussain et al., 2011). Essential oils and their components are gaining interest because of their relatively safe status, their wide acceptance by consumers and their exploitation for potential multi-purpose functional use.

Citrus essential oils are a mixture of volatile compounds and mainly consisted of monoterpene hydrocarbons (Sawamura et al., 2004). It is well known that essential oils from Citrus spp. have pronounced antimicrobial effect against both bacteria and fungi. Citrus essential oils could represent good candidates to improve the shelf life and the safety of minimally processed fruits (Lanciotti et al., 2004). Citrus essential oils are used in pharmaceutical, perfumery and food industries (Norajit et al., 2007). Moreover, increase in the emergence of new bacterial strains that are multi-resistant coupled with the nonavailability and the high cost of new generation antibiotics have resulted in increase morbidity and mortality (Lewis and Ausubel, 2006). So, investigations into the antimicrobial activities, mode of action and potential uses of plant essential oils have regained momentum. As essential oils are a rich source of biologically active compounds, there has been an increased interest in looking at antimicrobial properties of extracts from aromatic plants particularly essential oils.

Citrus oils of different species have been studied (Vlisidis and Israilidis, 1998; Kirbaslar and Kirbaslar, 2003). However, essential oil of C. limetta var. Mitha (a local variety) in Pakistan has yet not been studied. The aim of the present studies was to determine the chemical composition, antioxidant and antimicrobial activity of essential oil of $C$. limetta var. Mitha cultivated in Pakistan against different food borne pathogens of public health significance.

\section{MATERIALS AND METHODS}

Collection of plant materials and extraction of essential oil:

The fruit was purchased from the local market of Lahore then washed, peeled off and cut into small pieces. The cut peels (300 gm) were subjected to Hydro-distillation by using Dean-Stark assembly (Sattar, 1989). The distillate was removed and separated from water by using a separating funnel. $0.939 \mathrm{~g}$ of oil is collected and extracted twice with $20 \mathrm{ml}$ ether and was dried over $0.01 \mathrm{~g}$ anhydrous sodium sulphate and recovered pale yellow oil was stored for further studies.

\section{Gas chromatographic analysis}

Gas chromatographic analysis of the extracted peel oil was carried out on gas chromatograph (GC) of Agilent Technologies Inc., USA, operating in electron ionization mode at $70 \mathrm{eV}$ using co-injection techniques in order to identify its different components._A $0.2 \mu \mathrm{L}$ sample of the oil was injected and column was run under following conditions: Column, SE30 packed glass column; carrier gas, helium; flow rate, $30 \mathrm{ml} / \mathrm{min}$; detector, C-R4A (Shimadzu); chart speed, $3 \mathrm{~cm} / \mathrm{min}$; column temperature, $70^{\circ} \mathrm{C} / \mathrm{min}-5^{\circ} \mathrm{C} / \mathrm{min}$. Various components were identified by their retention time and confirmed by injecting authentic standard samples. The percentage composition of the essential oil was obtained with the help of linked computing integrator (Shimadzu C-R4A).

\section{Antibacterial and antifungal activities of $C$. limetta var. Mitha peel oil}

The agar disc diffusion method was employed for the determination of antibacterial and antifungal activity of $C$. limetta_peel oil following the procedure of Baydar et al. (2004) against different food borne pathogens including bacteria (Staphylococcus aureus ATCC 25923, Bacillus subtilis ATCC 6633, Bacillus cereus ATCC 14579, Lactobacillus acidophilus ATCC 4356 , Escherichia coli ATCC 25922, Salmonella typhymurium ATCC 14028 and Enterobacter areogene ATCC 13048) and fungi (Aspergillus niger ATCC 16404, Aspergillus flavus ATCC 204304, Aspergillus fumigatus KM 8001, Aspergillus ficuum ATCC 66876, Aspergillus oryzae ATCC 10124, Fusarium oxysporum ATCC 48122, Penicillum digitatum ATCC 201167, Fusarium miniformes MAY 3629, Fusarium saloni MAY 3636., Candida utilis ATCC 9950). Standard culture media (CM139, CM271, CM145, CM69, CM7 and CM201) from Oxoid were employed through-out the present investigation for the purpose of culture maintenance at their respective temperatures that is $25^{\circ} \mathrm{C}$ for fungi and 37 and $30^{\circ} \mathrm{C}$ for bacteria. $A$. niger and $A$. flavus from Guava fruit, $A$. fumigatus from Stored citrus fruit, $A$. ficuum from Lemon, F. oxysporium from Onion, $C$. utilus and $P$. digitatum from Bread, S. aureus and $L$. acidophilus from milk, $B$. subtilis and $B$. cereus from cheese, $E$. coli from Aloe vera gel, $S$. typhymurium from cake mix sample and $E$. aerogenes from baby food origin were obtained.

The growth medium were prepared, autoclaved and transferred aseptically to sterilized petri plates. Microbial cultures which were maintained in test tube slants were transferred to their respective media petri plates. Sterile and dried $6 \mathrm{~mm}$ paper discs (Difco, USA) were impregnated with $20 \mu \mathrm{l}$ filtered sterilized $(0.45 \mathrm{~mm}$ Millipore filter) newly extracted $C$. limetta var. Mitha peel oil. These oil-impregnated discs were dried under laminar flow cabinet. The 
Table 1. Chemical composition of essential oil of Citrus limetta var. Mitha (sweet lime) by gas chromatography.

\begin{tabular}{lcccc}
\hline Component & Peak Number & Retention time $(\mathbf{m i n})$ & Peak area & Percentage \\
\hline$\alpha$-thujene & 1 & 1.354 & 5301 & 0.0688 \\
$\alpha$-pinene & 2 & 1.483 & 2927 & 0.0381 \\
$\beta$-pinene & 3 & 2.006 & 2306 & 0.0299 \\
$\rho$-cymene & 5 & 4.933 & 29758 & 0.3861 \\
Camphene & 6 & 5.924 & 137681 & 1.7865 \\
Limonene & 7 & 7.468 & 7396614 & 95.9768 \\
$\alpha$-terpinene & 8 & 8.658 & 25714 & 0.3337 \\
Neral & 9 & 9.967 & 22405 & 0.2907 \\
Geraniol & 10 & 11.273 & 28059 & 0.3641 \\
Geranial & 11 & 11.833 & 2427 & 0.0315 \\
Citronellal & 12 & 12.429 & 7329 & 0.0951 \\
$\alpha$-terpinol & 13 & 13.171 & 24586 & 0.3191 \\
Un-known & 14 & 14.671 & 4246 & 0.0551 \\
Un-known & 15 & 15.563 & 1492 & 0.0193 \\
$\alpha$-humulene & 17 & 18.263 & 3931 & 0.0511 \\
$\beta$-bisabolene & 19 & 19.971 & 9834 & 0.1276 \\
$\beta$-sinesol & 20 & 21.484 & 2062 & 0.0268 \\
\hline
\end{tabular}

discs were placed on freshly seeded microbial lawns (4 discs in each plate) with a control. $20 \mu \mathrm{l}$ of sterile water was used as a negative control, whereas streptomycin $(20 \mu \mathrm{l} / \mathrm{disc})$ as a positive control for bacteria and fluconazole $(20 \mu \mathrm{l} / \mathrm{disc})$ for fungi. All experiments were conducted in triplicate. The petri plates were incubated at their respective temperatures and zones of inhibition thus developed against tested microorganisms were measured in millimeters after a period of $24 \mathrm{~h}$ for yeast ( $C$. utilis) and bacteria and $48 \mathrm{~h}$ for other fungi and similarly at 48 and $96 \mathrm{~h}$ (Table 2). The results of antimicrobial activity of peel oil against different microorganisms were expressed as resistant, intermediate and sensitive.

\section{Antioxidant activity of $C$. limetta var. Mitha peels oil}

Antiradical activity was evaluated by measuring the scavenging activity of the examined $C$. limetta var. Mitha peel oil on the 2, 2diphenyl-1-picrylhydrazil (DPPH) radical. The DPPH assay was performed as described by Epsin et al. (2000). The samples (100 $\mu \mathrm{l}$ each) were mixed with $3 \mathrm{ml}$ of DPPH solution. The absorbance of the resulting solutions and the blank (with only DPPH and no sample) were recorded after an incubation time of $30 \mathrm{~min}$ at room temperature against ascorbic acid as a positive control. For each sample, three replicates were recorded. The disappearance of DPPH was measured spectrophotometrically at $517 \mathrm{~nm}$. The percentage of radical scavenging activity was calculated using the following equation

DPPH scavenging effect $(\%)=\left(A_{0}-A_{1}\right) / A_{0} \times 100$

Where, $A_{0}$ is the absorbance of the control at $30 \mathrm{~min}$ and $A_{1}$ is the absorbance of the sample at $30 \mathrm{~min}$.

\section{RESULTS AND DISCUSSION}

\section{Chemical analysis of Citrus limetta var. Mitha peel oil}

Hydro distillation of the peels of $C$. limetta var. Mitha yielded $0.313 \%$ oil. Yield of citrus essential oil differs with individual plant species ranging in most cases from 0.2 to 2.0\% (Anonymous, 2004). Ahmad et al. (2006) studies showed that oil yield of Mousami, Grape fruit, Kinnow and Fewtrell's was $0.98,0.73,0.32$ and $0.22 \%$, respectively. This difference in the percentage yield of peel oil might be due to seasonal variation or time of harvest of citrus fruit.

Gas chromatographic analysis revealed that limonene which is the chief constituent in about all the citrus oils was the largest single monoterpene hydrocarbon $(95.97 \%)$ of the C. limetta var. Mitha peel oil (Table 1$)$. Limonene is also present, though in slightly lower quantities, in the oils of other major fruits, where it ranges from $85-95 \%$. Similarly, Turkish lemon peel oil and sweet orange have high content of monoterpene hydrocarbons $(89.9 \%)$ with limonene (61.8 and $91.6 \%$, respectively) as major constituent (Kirbaslar et al., 2009). Tao et al. (2009) also studied the GC/MS analysis of essential peel oil of Bingtang sweet orange (Citrus sinensis Osbeck) and found that limonene was observed dominant $(77.49 \%)$, followed by myrcene $(6.27 \%)$, a-farnesene (3.64\%), $\quad y$-terpinene $\quad(3.34 \%), \alpha$-pinene $\quad(1.49 \%)$, sabinene $(1.29 \%)$ and other minor components. Scientists from different fields carried out comparative studies on the chemical composition of essential oils taken from Italian sweet lime and bergamot oil and found that both contained similar composition but the former had more limonene and less linalyl acetate content (Carpano et al., 2003; Haristoy et al., 2003). The second major constituent in our studied peel oil after limonene was camphene $1.78 \%$ followed by $\rho$-cymene $0.38 \%$, Geraniol $0.36 \%$, $\alpha$-terpinene $0.33 \%$, $\alpha$-terpineol $0.31 \%$, Neral $0.29 \%$, $\beta$-bisabolene $0.12 \%$. Similarly, it was found 
Table 2. Anti-microbial activity of essential oil of Citrus limetta var. Mitha (Sweet Lime) peel against different pathogens.

\begin{tabular}{|c|c|c|c|c|c|c|c|}
\hline \multirow{2}{*}{$\begin{array}{l}\text { Tested } \\
\text { Microorganism }\end{array}$} & \multirow{2}{*}{$\begin{array}{c}\text { Incubation } \\
\text { Temperature }\left({ }^{\circ} \mathrm{C}\right) \\
\text { and Culture media }\end{array}$} & \multicolumn{2}{|c|}{ Inhibition Zone (mm) } & \multirow{2}{*}{$\begin{array}{l}\text { Percentage decrease } \\
\text { in inhibition zone } \\
(\mathrm{mm}) \text { after } 96 \mathrm{~h}\end{array}$} & \multirow{2}{*}{$\begin{array}{c}\text { Positive control } \\
\text { Streptomycin// } \\
\text { Fluconazole }(20 \mu \mathrm{\mu} / \mathrm{disc})\end{array}$} & \multirow[b]{2}{*}{$\begin{array}{l}\text { Negative } \\
\text { Control }\end{array}$} & \multirow[b]{2}{*}{ Efficiency } \\
\hline & & $\begin{array}{l}\text { After } 24 \mathrm{~h} \text { (bacteria and } \\
\text { yeast) } 48 \mathrm{~h} \text { for fungi }\end{array}$ & $\begin{array}{l}\text { After } 48 \mathrm{~h} \text { (bacteria and } \\
\text { yeast) } 96 \mathrm{~h} \text { for fungi }\end{array}$ & & & & \\
\hline Aspergillus niger & $25 \&$ M139 & 22 & 17 & 26.22 & 20 & 0 & $S$ \\
\hline Aspergillus flavus & $25 \&$ M139 & 19 & 16 & 18.97 & 12 & 0 & 1 \\
\hline $\begin{array}{l}\text { Aspergillus } \\
\text { fumigatus }\end{array}$ & $25 \&$ M139 & 14 & 12 & 15.71 & 10 & 0 & I \\
\hline $\begin{array}{l}\text { Aspergillus } \\
\text { ficuum }\end{array}$ & $25 \&$ M139 & 12 & 10 & 16.67 & 8 & 0 & 1 \\
\hline $\begin{array}{l}\text { Fusarium } \\
\text { oxysporium }\end{array}$ & $25 \&$ M139 & 11 & 10 & 10.90 & 9 & 0 & $\mathrm{R}$ \\
\hline Candida utilus & $25 \&$ M139 & 13 & 11 & 16.92 & 11 & 0 & I \\
\hline $\begin{array}{l}\text { Pencillium } \\
\text { digitatum }\end{array}$ & $25 \&$ M139 & 18 & 15 & 17.98 & 17 & 0 & I \\
\hline $\begin{array}{l}\text { Staphylococcus } \\
\text { aureus }\end{array}$ & $37 \&$ M145 & 21 & 18 & 16.82 & 20 & 0 & 1 \\
\hline Bacillus subtilis & $37 \&$ M271 & 26 & 22 & 21.13 & 24 & 0 & S \\
\hline Bacillus cereus & $37 \& M 271$ & 28 & 21 & 27.46 & 27 & 0 & S \\
\hline $\begin{array}{l}\text { Lactobacillus } \\
\text { acidophilus }\end{array}$ & $45 \& M 361$ & 18 & 16 & 14.75 & 14 & 0 & I \\
\hline
\end{tabular}

that citronellal, geranial, $\alpha$-pinene, $\beta$-pinene, $\alpha$ thujene, $\beta$-sinesol and $\alpha$-humulene were present in minute amount (less than $0.1 \%$ ).

Our results were in conformity with the previous findings as limonene, $\gamma$ - terpinene, $\beta$-pinene, $\alpha$ pinene, myrcene, valencene, linalool, octanal, decanal, and butyle butyrate has been found as the major constituents through gas chromategraphic separation of essential oils from vietnames pummelo, sweet orange, tangerine, bergamote, grapefruit peel and mousami (Gancel et al., 2002; Hognadottir and Russell, 2003; Khanum et al., 2004). Steam-distilled volatile peel oil of Indian orange when analyzed through GC and GC-MS, limonene was found more dominant followed by myrcene, $\alpha$-terpinolene and $\beta$-pinene (Kirbaslar and Kirbaslar, 2003). Almost similar results were reported by Feger et al. (2003) and Tu et al. (2003) while working on orange and tangerine essential oils. Comparatively, however, the gas chromatographic separation of the citrus peel oils of Pakistani origin showed both quantitative and qualitative variation in volatiles composition. Chemical composition of essential oils of different species of citrus varied significantly, which may be due to the difference in their genetic makeup (Ahmad et al., 2006).

\section{Antibacterial and antifungal activities of $\mathrm{C}$. limetta var. Mitha peel oil}

The results of antibacterial and antifungal activity of C. limetta var. Mitha peel oil, investigated against different food borne pathogens by disc diffusion method, are presented in Table 2. It was found in the present study that peel oil exhibited maximum zone of inhibition against $B$. cereus ATCC $14579(28 \mathrm{~mm})$ and B. subtilis ATCC 6633 $(26 \mathrm{~mm})$ followed by S. aureus ATCC 25923 (21 $\mathrm{mm}$ ) after $48 \mathrm{~h}$ of incubation at $37^{\circ} \mathrm{C}$, whereas the minimum zone of inhibition was shown by $F$. oxysporum ATCC $48122(11 \mathrm{~mm})$ after $48 \mathrm{~h}$ of incubation at $25^{\circ} \mathrm{C}$ in comparison with streptomycin/fluconazole at $20 \mu \mathrm{l}$ per disc. However, A. niger ATCC 16404, A. flavis ATCC 204304, A. fumigates KM 8001, A. ficuum ATCC 66876, C. utilus ATCC 9950, P. digitatum ATCC 201167, E. coli ATCC 25922, L. acidophilus ATCC 4356, S. typhymurium ATCC 14028 and E. aerogenes ATCC 13048 gave 22, 19, 14, 12, 13, $18,13,18,17$ and $13 \mathrm{~mm}$ of zone of inhibition, 


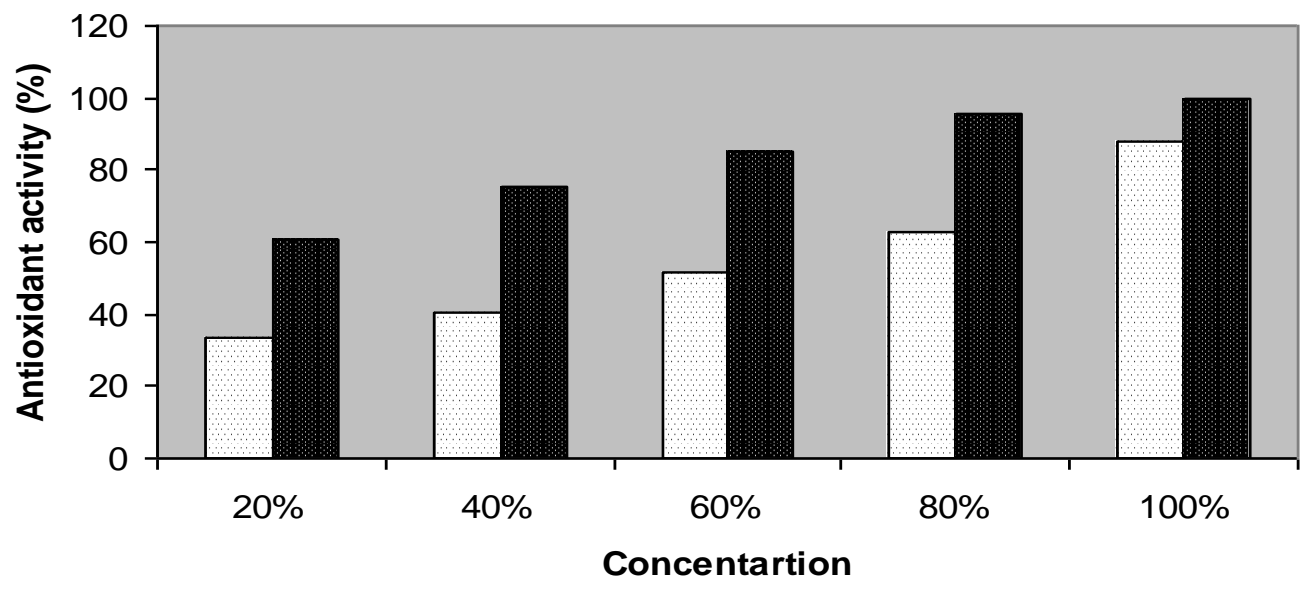

$\square$ Citrus limetta Ascorbic acid

Figure 1. Percentage antioxidant activity of essential oil of Citrus limetta var. Mitha (sweet lime) in comparison with ascorbic acid as standard reference evaluated by DPPH assay.

respectively after $48 \mathrm{~h}$ of their respective incubation temperatures. The essential oils from two cultivars of tropical citrus, including $C$. hystrix and $C$. aurantifolia exhibited antimicrobial activity against $B$. cereus, $S$. aureus and S. typhi (Chaisawadi et al., 2003). Mahmud et al. (2009) results also revealed that $C$. acida peel oil exhibited maximum zone of inhibition against $B$. subtilis. Many other studies also revealed that $\alpha$--pinene, limonene and linalool have a strong antibacterial activity (Mecciaa et al., 2007; Filipowicz et al., 2003; Koji et al., 2004). Kekuda et al. (2009) studied antifungal activity of steam distillates of peels of different citrus fruits namely $C$. limetta, $C$. sinensis and $C$. limon against Aspergillus species and found that $C$. limetta was found to be superior to inhibit the growth of tested fungi. Johann et al. (2007) studies also indicated that the peels of the Citrus species present substantial antimicrobial properties. Essential oils usually occur as complex mixtures and their activity can generally be accounted for in terms of their major monoterpenoid components. According to Sikkema et al. (1995), the antimicrobial action of monoterpenes suggests that they can easily diffuse into or penetrate through the damage cell membrane structures of microorganisms. Therefore, essential oils being rich in terpenes have been shown to possess good antibacterial activity (Afolayan and Ashafa, 2006). It is further reported that the antimicrobial property of the essential oil is because of the fact that it contains active components which influence certain metabolic functions of microbial cells (Chaisawadi et al., 2003). In addition, some components that occur in lesser amount may also contribute to the antimicrobial activity of the oil, involving probably some type of synergism with the other active compounds (Matosyoh et al., 2007). It was also found during the present investigation that the tested oil has shown nearly equal antimicrobial effects on both gram positive ( $B$. subtilis ATCC 6633, S. aureus ATCC 25923, B. cereus ATCC 14579, L. acidophilus ATCC 4356) and gram negative (E. coli ATCC 25922, S. typhymurium ATCC 14028, E. aerogenes ATCC 13048) bacterial strains in culture media. Similar kind of observations were also made by Shahzad et al. (2009) and Ravi et al. (2010) indicating that the essential oil of citrus peel was active against all tested bacteria including both gram positive and negative cultures.

The present investigation for the assessment of antimicrobial activity of $C$. limetta var. Mitha peel oil against different microbes of public health significance indicated a percent decrease in clear zone of inhibition after $96 \mathrm{~h}$ ranging between 11 to $27 \%$ for different fungi and bacteria. This decrease in clear zone of inhibition after $96 \mathrm{~h}$ by sterilized sweet lime peel oil preparation may be either due to inactivation or low concentrations of diffusible water soluble active constituents. Our findings are in agreement with earlier reports (Siddiqui et al., 1996), where a decrease in inhibitory zone from 15 to $26 \mathrm{~mm}$ after a period of $96 \mathrm{~h}$ of incubation was observed to cause decrease from 9.52 to $34.8 \%$ against the tested strains.

\section{Antioxidant activity of Citrus limetta var. Mitha peel oil}

The ability of essential oils to act as a donor for hydrogen atoms or electrons in the transformation of DPPH radical into its reduced form DPPH-H (which is measured spectrophotometrically) gives them antioxidant activity characteristic. The results of DPPH scavenging activity of C. limetta var. Mitha peel oil compared with ascorbic acid as a reference standard are shown in Figure 1 indicating that it has slightly lower antioxidant activity comparative to reference standard, ascorbic acid, being a strong anti- 
oxidant reagent. The essential peel oil of $C$. limetta var. Mitha peel oil was able to reduce the stable radical DPPH to yellow-colored DPPH-H reaching $87.77 \%$ of $\mathrm{DPPH}$ scavenging effect at its $100 \%$ concentration whereas the reference standard, ascorbic acid, gave a $99.67 \% \mathrm{DPPH}$ scavenging effect at its $100 \%$ concentration. Mahmud et al. (2009) studies also indicated that essential peel of $C$. acida var. sour lime showed $91.7 \%$ of DPPH scavenging effect at its $100 \%$ concentration compared with ascorbic acid as a reference standard. Sacchetti et al. (2005) studies also showed that essential oils of Cananga odorata, Cymbopogon citratus, Rosmarinus officinalis and Curcuma longa notably reduced the concentration of DPPH free radical indicating their strong antioxidant activities. Choi et al. (2000) studies also showed that radical-scavenging activities using DPPH of 31 kinds of citrus essential oils were comparable with or stronger than that of Trolox (standard antioxidant).

In conclusion, the Chemical analysis of essential oil extracted from C. limetta var. Mitha (Sweets lime) showed that limonene $(95.98 \%)$ was found as major component followed by camphene $(1.79 \%)$, while the remaining terpenes were less than $1 \%$. The results of our study showed that $C$. limetta var. Mitha (sweet lime) peel oil have the probability to be applied as a natural constituent of food preservations, cosmetics and medicines as they exhibit a strong antioxidant, antibacterial and antifungal activity against food borne pathogens.

\section{REFERENCES}

Afolayan AJ, Ashafa AOT (2006). Chemical composition and antimicrobial activity of the essential oil from Chrysocoma ciliata L. leaves. J. Med. Plants Res. 3: 390-394.

Ahmad MM, Rehman S, Iqbal Z, Anjum FM, Sultan JI (2006). Genetic variability of essential oil composition in four citrus fruit species. Pak. J. Bot. 38: 319-324.

Ahamd MM, Rehman S, Anjum FM, Bajwa EE (2006). Comparative physical examination of various citrus peel essential oils. Int. J. Agri. Bio. 8: 186-190.

Anonymous (2004). Citrus Fruits. http://alfa.ist.utl.pt/ field/flaves/ sec3/citrus.html. Accessed on 17/9/2004.

Baydar H, Sagdic O, Ozkan G, Karadogan T (2004). Antibacterial activity and composition of essential oil from Origanam, Thymbra and Satureja species with commercial importance in Turkey. Food Conf. 15: 169-172.

Carpano SM, Spegazzini ED, Rossi JS, Castro MT, Debenedetti SL (2003). Antifungal activity of Terminalia Australia. Fitoterapia, 74: 294-297.

Chaisawadi S, Thongbutr D, Methawiriyasilp W, Chaisawadi A, Pitakworarat N, Jaturonrasamee K, Khemkhaw J, Tanuthumchareon W (2003). Preliminary Study of Antimicrobial Activities on Medicinal on Herbs of Thai Food's Ingredients. The Third World Congress on Medicinal and Aromatic Plants. Chiang Mai, Thailand.

Choi HS, Song HS, Ukeda H, Sawamura M (2000). Radical-Scavenging Activities of Citrus Essential Oils and Their Components: Detection Using 1, 1-Diphenyl-2-picrylhydrazyl. J. Agr. Food Chem. 48 : 41564161.

Epsin JC, Soler-Rivas C, Wichers HJ (2000). Characterization of the total free radical scavenger capacity of vegetable oils and oil fractions using 2, 2-diphenyll-1-picrylhydrazyl radical. J. Agri. Food Chem. 48: 648-56.

Feger W, Brandauer H, Ziegler H (2003). Analytical investigation of Murcott (Honey) Tangerine oil. J. Essential Oil Res. 15: 143-147.
Filipowicz N, Kamiñski M, Kurlenda J, Asztemborska M (2003). Antibacterial and antifungal activity of juniper berry oil and its selected components. Phyt. Res. 17: 227-231.

Gancel A, Olle DL, Ollitrault P, Luro F, Brillouet JM (2002). Leaf and peel volatile compounds of an inter-specific citrus somatic hybrid ( $C$. aurantifolia and C. paradisi). Flav. Frag. J. 17: 416-424.

Haristoy X, Angioi-Duprez K, Duprez A, Lozniewski A (2003). Efficacy of sulforaphane in eradicating Helicobacter pylori in human gastric xenografts implanted in nude mice. Anti. Agents Chemo. 47: 3982 3984.

Hognadottir A, Russell RI (2003). Identification of aroma active compounds in orange essence oil using gas chromatographyolafactometry and gas chromatography-mass spectrometry. J. Chrom. 998: 201-211.

Hussain Al, Anwar F, Iqbal T, Bhatti IA (2011). Antioxidant attributes of four Lamiaceae essential oils. Pak. J. Bot. 43: 1315-1321.

Jacquemond C, Curk F, Zurru R, Ezzoubir D, Kabbage FL, Ollitrault R (2002). Roots stocks, a key component in sustainable citrus growing, quality of fresh and processed citrus fruits, Montellier, France, 10-12.

Johann S, de Oliveira VL, Pizzolatti MG, Schripsema J, Braz-Filho R, Branco A, Smania A (2007). Antimicrobial activity of wax and hexane extracts from Citrus spp. peels. Mem. do Inst.Oswaldo Cruz. 102: 0074-0276.

Kekuda TRP, Aiyar MB, Rohini TR, Nayana KV, Swathi D (2009). Preliminary Studies on In Vitro antifungal activity of Citrus peel distillates. Trade Sci. Inc. 5: 9.

Khanum R, Mahmud S, Waheed A, Nazir T (2004). Physico-chemical studies of the essential oil of $\mathrm{C}$. sinensis (var. Mousambi). Chemical Society of Pakistan, pp. 209. 4th Intl. and $14^{\text {th }}$ National Chemistry Conference. Organized by Chemical Society of Pakistan, Lahore Chapter.

Kirbaslar FG, Kirbaslar SI (2003). Composition of cold pressed bitter orange oil from Turkey. J. Essen. Oil Res. 15, 6-9.

Kirbaslar FG, Tavman A, Dulger B, Turker G (2009). Antibacterial activity of Turkish Citrus Peel oils. Pak. J. Bot. 41(6): 3207-3212.

Koji YK, Yamamoto T, Kawai Y, Inoue N (2004). Enhancement of antilisterial activity of essentials oil constituents by nisin and diglycerol fatty acid ester. Food Micro. 21: 283-289.

Lanciotti R, Gianotti A, Patrignani F, Belletti N, Guerzoni EM, Gardini F (2004). Use of natural aroma compounds to improve shelf-life and safety of minimally processed fruits. Trends in Food Sci. Technol. 15: 201-208.

Lewis K, Ausubel F (2006). Focus on antibacterials. Nature Biotechnology, 24: 1453-1602.

Liu H, Qiu N, Ding H, Yao R (2008). Polyphenols contents and antioxidant capacity of Chinese herbals suitable for medicinal or food uses. Food Res. Int. 41: 363-370.

Mahmud S, Saleem M, Siddiqui S, Ahmad R, Khanum R, Parveen Z (2009). Volatile components, antioxidant and antimicrobial activity of Citrus acida var. sour lime peel oil. J. Saudi Chem. Soc. 12: 195-198.

Matosyoh J, Kiphino JJ, Karubiu NM, Hailstorks TP (2007). Chemical composition and antimicrobial activity of essential oil of Tarchonanthus camphoratus. Food Chem. 100: 1183-1187.

Mecciaa G, Luis B, Judith V, Tulia D, Alfredo U (2007). Composition and antibacterial screening of the essential oils of Leaves and Roots of Espeletiopsis angustifolia Cuatrec. Nat. Product Comm. 2: 1221 1224.

Mondello L, Casilli A, Tranchida PQ, Dugo P (2005). Comprehensive two dimensional GC for the analysis of citrus essential oils. Flav. Frag. J. 20: 136-140.

Murphy MC (1999). Plant products as antimicrobial agents. Clin. Micro. Rev. 12: 564-669.

Nasir E, Ali SI (1978). Flora of West Pakistan, pp 436-437 University of Karachi.

Norajit K, Akunjit NL, Kerdchuen O (2007). Antibacterial activity of five Zingebraceae essential oils. Molecule, 12: 2047-2060.

Nostro M, Germano V, DÁngelo V, Cannatelli M (2000). Extraction methods and bioautography for evaluation of medicinal plant antimicrobial activity. Lett. Appl. Micro. 30: 379-384.

Pierangeli G, Vital G, Rivera LW (2009). Antimicrobial activity and cytotoxicity of Chromolaena odorata (L. f.) King and Robinson and Uncaria perrottetii (A. Rich) Merr. Extracts. J. Med. Plants Res. 3: 
511-518.

Ravi KU, Dwivedi P, Ahmad S (2010). Screening of antibacterial activity of six plants essential oils against pathogenic bacterial strains. Asian J. Med. Sci. 2: 152-158.

Sacchetti G, Maietti S, Muzzoli M, Scaglianti S, Manfredini M, Radice M, Bruni R (2005). Comparative evaluation of 11 essential oils of different origin as functional antioxidants, antiradicals and antimicrobials in foods. Food Chem. 91: 621-632.

Sattar A. Perfumes and Flavour (1989). Proceedings of the First National Symposium on Essential Oil, PCSIR Laboratories Complex, Lahore. pp: 7-12.

Sawamura M, Son US, Choi HS, Kim MSL, Phi NTL, Fears M, Kumagai C (2004). Compositional changes in commercial lemon essential oil for aromatherapy. Int. J. Aroma. 4: 27-33.

Shabbir MK, Nadeem R, Mukhtar H, Anwar F, Mumtaz MW (2009). Physico-chemical analysis and determination of various chemical constituents of essential oil in Rosa centifolia. Pak. J. Bot. 41: 615620.
Shahzad K, Nawaz S, Ahmad R, Mahmud S, lqbal Z, Saeed K (2009). Evaluation of antioxidant and antimicrobial activity of essential oil of Tangerine fruit peel. Pak. J. Bio. Mol. Bio. 42: 4-7.

Siddiqui RR, Hamid A, Sultan SC, Ehtheshammudin AFM, Shireen S (1996). Antimicrobial activity of essential oils. Pak. J. Sci. Ind. Res. 39: 43-47.

Sikkema J, de Bront JAM, Poolman B (1995). Mechanisms of membrane toxicity of hydrocarbons. Micro. Rev. 59: 201-222.

Tao N.-g, Liu Y-j, Zhang M.-I (2009). Chemical composition and antimicrobial activities of essential oil from the peel of bingtang sweet orange (Citrus sinensis Osbeck). Int. J. Food Sci. Tech. 44: 12811285.

Tu NTM, Onish Y, Choi HS, Kondo Y, Ukeda H, Sawamura M (2003). Characteristic odor components of Citrus sp. (Kiyookadaidal) cold pressed peel oil. Flav. Frag. J. 18: 515-520.

Vlisidis AG, Israilidis KI (1998). Analysis of essential oil fractions from Greek Citrus species, Chemika Chronika, Genike Ekdose. 60: 75 78. 